Article

\title{
Comparative Study of AC and Positive and Negative DC Visual Corona for Sphere-Plane Gaps in Atmospheric Air
}

\author{
Jordi-Roger Riba ${ }^{1, *(\mathbb{C})}$, Andrea Morosini ${ }^{2}$ and Francesca Capelli ${ }^{3}{ }^{\mathbb{B}}$ \\ 1 Electrical Engineering, Universitat Politècnica de Catalunya, Rambla Sant Nebridi 22, 08222 Terrassa, Spain \\ 2 Engineering Department, Università Degli Studi del Sannio, Piazza Roma 21, 82100 Benevento, Italy; \\ mid.90@hotmail.it \\ 3 R\&D Department, SBI Connectors España S.A.U., Albert Einstein, 5-7, 08635 Sant Esteve Sesrovires, Spain; \\ francesca.capelli@sbiconnect.es \\ * Correspondence: riba@ee.upc.edu; Tel.: +34-937-398-365
}

Received: 14 September 2018; Accepted: 3 October 2018; Published: 8 October 2018

\begin{abstract}
Due to the expansion of high-voltage direct current (HVDC) power systems, manufacturers of high-voltage (HV) hardware for alternating current (ac) applications are focusing their efforts towards the HVDC market. Because of the historical preponderance of ac power systems, such manufacturers have a strong background in ac corona but they need to acquire more knowledge about direct current $(\mathrm{dc})$ corona. Due to the complex nature of corona, experimental data is required to describe its behavior. This work performs an experimental comparative analysis between the inception of ac corona and positive and negative dc corona. First, the sphere-plane air gap is analyzed from experimental data, and the corona inception voltages for different geometries are measured in a high-voltage laboratory. Next, the surface electric field strength is determined from finite element method simulations, since it provides valuable information about corona inception conditions. The experimental data obtained are fitted to an equation based on Peek's law, which allows determining the equivalence between the visual corona surface electric field strength for ac and dc supply. Finally, additional experimental results performed on substation connectors are presented to further validate the previous results by means of commercial high-voltage hardware. The results presented in this paper could be especially valuable for high-voltage hardware manufacturers, since they allow determining the dc voltage and electric field values at which their ac products can withstand free of corona when operating in dc grids.
\end{abstract}

Keywords: visual corona; direct current; alternating current; finite element method

\section{Introduction}

New or replacement hardware intended for use in high-voltage systems must provide adequate corona performance over the expected life, under specified service conditions [1]. The correct detection and evaluation of the corona inception conditions is of special interest during the design stage of such high-voltage components. This point has been highlighted in different works analyzing dielectric-coated stranded conductors [2], valve hall fittings [3], or point-plane [4] and sphere gaps [5] among others.

Corona discharges are self-sustained electric discharges, which ionize a reduced region around the high-voltage electrode. They occur when the surface electric field exceeds the critical inception value, as recognized in $[6,7]$ when analyzing transmission power lines. When the surface electric field is above the critical inception value, air molecules can be ionized [8] due to electron collision, thus developing an electron avalanche process [9]. However, due to the complex molecular reactions 
within the gas during the discharge process, the exact physical mechanism of the discharges is still unclear [10].

Corona performance is an important design criterion for both direct current (dc) and alternating current (ac) high-voltage (HV) applications [4]. Corona produces unnecessary loss of energy [1], or audible and luminous discharges as recognized by Bian et al. [11]. Corona effect also generates conducted and radiated TV and radio interference, mainly due to the corona pulses generated during the positive half-cycle, as pointed out by Wang et al. [10]. This effect also generates ozone and chemical reactions [12], thus producing chemical effects on nearby surfaces [13], changes in the ionized field in the surroundings of the line [14], and finally, degradation of the insulation performance [15].

Corona effect involve low-power discharges that occur at atmospheric pressure [16]. Such discharges are generated by intense electric fields generated by sharp edges of an electrode, wires of small diameter, needles, or sharp electrodes. Since corona activity is related to the electric field strength at the surface of the high-voltage electrodes, the voltage gradient must be limited to minimize its effects [4]. Therefore, it is essential to perform a correct evaluation of the corona phenomenon during the design stage of transmission lines and related high-voltage equipment in order to limit its effects [7].

Nowadays, high-voltage direct current (HVDC) power systems are an interesting alternative for bulk electric power transmission due to several advantages, including reduced power losses, the possibility of power transmission between unsynchronized ac power systems, helping to increase power system stability, or environmental benefits due to reduced right-of-way requirements, among others [17]. According to [18], about 30\% of the planned investment in Europe for new electrical transmission infrastructure is related to HVDC technology. The number of HVDC projects is increasing due to several factors, including the integration of renewables, mainly for offshore wind in coastal areas, the need of transmitting large amounts of power from remote locations, the need of interconnecting different systems, or the introduction of ultra-high voltage direct current (UHVDC) systems, among others [18].

Corona discharges exhibit different forms, which depend on the geometry of the electrode and the polarity of the voltage applied, among others. The discharge mechanism and the space charge distribution of dc corona under non-uniform electric fields are quite complex and differ from those of ac corona [19]. It is known that negative and positive polarity coronas exhibit different voltage-current characteristics, mainly due to the great mass difference between positive ions and electrons [20]. Unipolar and bipolar coronas also show different behavior due to the polarity and nature mechanisms related to ionization and recombination of the ionized species involved. In all cases, the current density produced by corona discharges is greatly affected by the magnitude of the electric field, the geometry of the electrode and the space charge distribution.

Two main regions coexist in the gap between the two electrodes. The ionization region is the region closest to the high-voltage electrode, which has a typical size of several millimeters, and an intense electric field, which allows sustainment of the ionization process. The drift or low-field region is located between the limit of the ionization region and the collecting electrode or ground plane, thus filling the inter-electrode space. In this region, the electric field is unable to sustain the ionization process [21]. The low-field drift region can act as a large impedance connected in series with the ionization region, thus stabilizing corona activity [13].

The space charge usually limits the magnitude of the discharge, since the ions emitted by the plasma surrounding the high-voltage electrodes tend to accumulate within the inter-electrode region. Therefore, higher voltages are required to raise the discharge current, although when increased sufficiently, due to the additional charge carriers generated, a spark discharge can be produced [16]. The electric field can be split in two components, the geometric electric field and the component due to the accumulated space charge [22]. According to [7], the space charge tends to decrease slightly the magnitude of the corona inception electric field, usually less than $3 \%$, thus being almost negligible [3]. 
Although the corona inception voltage can be measured, the corona inception electric field is difficult to measure.

Under dc supply, the space charge is mainly composed of two types of current-carrying species, small air ions and charged aerosols (particles suspended in the air), which exhibit different mobility. Small air ions exhibit a higher mobility, thus migrating quicker towards the ground. The intense electric field at the surface of the high-voltage electrodes can ionize air molecules near the electrodes. Ionized air molecules during the corona process undergo many collisions with other molecules, thus evolving fast from electrons and singly charged molecules and atoms, to singly charged molecular clusters. The small air ions generated under dc coronas near the high-voltage electrode experiment a force due to the electric field of constant polarity.

In the literature it is reported that in several geometries such as needle-plane $[19,23]$ or sphere-plane [20], among others, negative corona presents lower inception voltage than positive corona. However, the breakdown voltage of positive geometries often occurs at lower voltage as proved in the works of Liu et al. for needle-plane gaps [19] and Wais et al. dealing with sphere-plane geometries [20].

Since most of the radiation produced during corona processes falls within the ultraviolet spectrum, corona discharges are not visible in daylight, so visual corona must be detected in total darkness [24]. By using high-performance digital cameras, more sensitivity is attained compared to the traditional naked eye observation [25]. It is worth noting that visual corona testing allows identifying the areas of high-voltage hardware, which are more prone to corona appearance, thus facilitating the application of corrective actions to obtain an optimal design under test. Although corona can also be detected by using specific equipment involving partial discharges or audible noise detectors as proved by Chen et al. [26], or radio interference voltage measurements [27], such methods do not provide a direct visual location of the corona discharge points, although, in some circumstances, and by using multiple sensors, they can locate the discharge points, as proved in the works of Dong et al. [28] and Robles et al. [29].

Due to the worldwide expansion of HVDC projects and markets, and their positive future projections, manufacturers of high-voltage hardware for ac power lines, including clamps, fittings, spacers, dampers, dead-ends or connectors among others, are focusing towards the HVDC market. Therefore, in order to reconvert existing high-voltage alternating current (HVAC) products for HVDC applications, a deep knowledge about the corona effect and inception conditions is required, as well as, the relationship between ac, positive and negative dc coronas and the respective inception conditions. Although there are many works dealing with corona, the vast majority of them analyze particular configurations under specific conditions, that is, positive or negative dc corona or ac corona.

To the authors' knowledge, there are virtually no works performing a practical and simultaneous comparative analysis between ac and dc positive and negative coronas, this being one of the novelties of this work. This paper tries to fill this gap, since it carries out a comparative analysis of the inception of ac, positive, and negative dc coronas for sphere-plane gaps and finds out a relationship based on Peek's law. This work also includes a case study, in which the corona behavior of a substation connector is analyzed under positive and negative dc and ac supply, these results being compared with those obtained with the sphere-plane gap. Such analysis can be very useful for high-voltage hardware manufacturers, since it can help to understand the conditions and limitations of applying their ac products for HVDC projects. Finite element method (FEM) simulations are conducted to determine the surface electric field strength during corona inception conditions. The results presented in this paper are based on extensive tests performed in a high-voltage laboratory. Therefore, this paper tries to provide experimental reference data for product design related to corona performance, especially to reconvert ac hardware to be applied in HVDC grids.

Section 2 describes the main features of dc and ac coronas, as well as the polarity effect and discusses Peek's law for sphere-plane gaps. Section 3 details the FEM simulations carried out in this work. Section 4 describes the experimental setup and the appearance of $\mathrm{dc}$ and ac visual coronas. 
Section 5 summarizes and analyzes the experimental results attained with the sphere-plane gap. Section 6 extends and compares the results attained with sphere-plane gaps to substation connectors. Finally, Section 7 summarizes the conclusions of this research.

\section{Alternating Current (ac) and Direct Current (dc) Coronas in Atmospheric Air}

\subsection{Dc Coronas in Atmospheric Air}

The integration of a growing number of renewable sources has led to the widespread use of more HVDC systems [30]. The discharge behavior under dc and ac supply is different, mainly due to the effects of the space charge generated. Even under dc supply, the behavior of positive and negative discharges is different [30]. It is a recognized fact that under dc supply, corona sources sometimes present an erratic corona behavior, which can be boosted by the presence of wind, since it can extinguish or reignite a corona source [1].

The space charge has little effect on the magnitude of the corona inception electric field, this effect being almost negligible during inception conditions, as recognized by Du et al. [3] and Lu et al. [7]. Therefore, for calculation purposes, during corona inception conditions, the electric field at the electrode surface can be calculated by only taking into account the geometric electric field component, thus neglecting the component due to the accumulated space charge [31]. During the corona discharge, the space charge tends to reduce the electric field strength within the region surrounding the high-voltage electrodes, so the magnitude of the electric field is difficult to predict [32].

Although there are many works analyzing dc coronas, the influence of voltage on corona development is still unclear, since both, the discharge mechanisms in non-uniform electric fields and the space charge formation processes during discharges are quite complex [19]. It is a recognized fact that in most dc applications, when increasing the amplitude of the applied voltage, negative corona occurs first, at lower voltage, as proved in the experimental work of Fuangpian et al. [23]. With the same atmospheric conditions, electrode and gap geometry, the spark breakdown condition under negative dc supply occurs at higher voltage than under positive dc supply, as proved in the experimental works of Pihera et al. [30] and Maglaras et al. [33]. Factors such as temperature, humidity, atmospheric pressure, electrode distance, or radius influence the corona inception voltage and discharge behavior [19].

\subsubsection{Negative Dc Coronas in Atmospheric Air}

Negative corona only occurs in electronegative gases, such as carbon dioxide, water vapor, or oxygen, since it is not possible in pure gases which do not present an affinity for electrons, such as helium, argon, hydrogen, or nitrogen [8]. Negative coronas produce thicker plasma regions (where significant number of electron-impact reactions take place) and more than fifty times the number of electrons than those produced in positive coronas. For negative coronas, the plasma region extends beyond the ionization region [8]. However, negative coronas generate a lower number of energetic electrons in the high-field region near the discharge electrode, compared to positive discharges [8].

When the electric field strength near the negative electrode is high enough to attract the positive ions, free electrons are generated mainly due to the collisions of the positive ions with the negative electrode. A minor number of electrons can also be released due to photon impact with neural molecules. Free electrons are pushed away from the negative electrode due to the repulsion of the electric field, thus generating avalanches of other free electrons and positive ions when colliding with atoms and molecules of air. A significant amount of excited atoms and molecules are also formed, and in the weak field or drift region, the generated electrons produce negative ions due to attachment with oxygen molecules. The space charge due to these species tends to accumulate with time, thus reducing the electric field strength within the ionization region [34].

Negative coronas usually show different forms or stages. In the negative needle-plane geometry, the initial form of discharge are the Trichel pulses (pulses of short duration depending on discharge current [35]), followed by pulseless corona streamers and spark discharge [34]. The density of negative 
corona streamers increases with the applied voltage. Close to the negative corona inception voltage, only one or a few streamers appear, but when the voltage increases, the number of streamers also increases and they appear more uniformly distributed [8].

\subsubsection{Positive Dc Coronas in Atmospheric Air}

The plasma region in positive coronas is thinner than that in negative coronas, and coincides with the ionization region [36]. Positive corona discharges produce less ozone compared to negative discharges [37] since the number of electrons generated is much lower than in negative coronas. However, positive corona streamers are more energy efficient in producing ozone [38]. Discharges associated to positive corona have greater amplitude and lower repetition rate than those under negative polarity [23]. Therefore, positive corona discharges present more severity.

Stable positive corona can be initiated in streamer or glow form, depending on gap configuration, electric field distribution, space charge effects, and atmospheric conditions, as described in [39]. According to [39], positive stabilized corona under inception conditions may initiate in both streamer or glow forms, depending on space charge field effects, which depend upon the three-dimensional electric field distribution and atmospheric conditions. Positive corona in air in point-plane discharge gaps, the most studied ones, can have different appearances, as burst pulses, streamers, steady glow or breakdown streamers, depending on the voltage applied [34]. However, positive streamer corona is difficult to control, since sparking occurs often [16].

\subsection{Power Frequency Ac Coronas in Atmospheric Air}

When increasing the amplitude of the ac voltage, negative corona appears first, although it is difficult to hear and see, as described in the IEC 61284 [40] and IEEE Std. 1829 standards [41]. Positive corona, which is generated during the positive half-cycle, appears at higher voltages in the form of streamers, but its inception is abrupt and easier to hear and see with the naked eye in a darkened laboratory, also producing higher levels of radio noise, so PD (partial discharge) and RIV (radio interference voltage) amplitudes also increase severely, as described in reference books [42,43]. The breakdown during the negative half-cycle occurs at higher voltage than during the positive half-cycle [42], except at low pressures. Therefore, the breakdown condition invariably occurs during the positive half-cycle of the voltage waveform [42].

Under power-frequency ac voltage, there is a slow unipolar corona transition from the firstto the second-half period of the voltage waveform. Therefore, in the vicinities of the high-voltage electrodes, the distribution and magnitude of the space charge change with time. For short discharge air gaps, the charge carriers are able to travel from one electrode to the other during one half-cycle, so the behavior of the discharge is similar to that under dc supply [34]. However, for longer air gaps, during one half-cycle, the charge carriers are unable to cross the air gap. In the course of the following half-cycle, the charge carriers of both signs will change their direction, thus moving towards the electrode of origin. Most of them will reach this electrode, although some of them will remain in the gap due to self-repulsion and diffusion phenomena. For longer gaps, the space charge density will be mainly confined in the central region of the discharge gap, which tends to increase with time. When the recombination tax and losses at the electrodes' walls are low, the electric field distribution near the electrodes can be altered. Therefore, positive and negative discharges can be generated when the instantaneous value of the ac voltage is below the inception voltage of dc discharges. The same is valid for the spark breakdown voltage. The current due the discharge depends on the space charge generated within the ionization region. The space charge moves due to the influence of the electric field, thus filling with charged particles the drift region. Because of the distribution of the space charge, the electric field strength is constant during the ionization process in a given half-cycle, its value being similar to that at the inception of corona of this polarity [34]. 


\subsection{The Polarity Effect}

The polarity effect is a phenomenon that affects the dielectric behavior of relatively long air gaps such as rod-plane, point-plane, or sphere-plane configurations with the plane grounded, when changing the polarity of the applied dc voltage. Due to this effect, the corona current, corona losses, and breakdown voltage are higher under negative dc polarity compared to positive dc polarity $[20,33,44]$. The corona inception electric field for negative corona is below to the corresponding positive one for relatively high values of the absolute humidity and air density, as reported in the experimental works of Mikropoulos et al. [31,39].

Positive corona generates less power loss than negative corona. In a point-plane or sphere-plane gap, the corona current increases with the applied voltage for both positive and negative dc supply, although the negative polarity current is higher than the positive one due to the effect of the space charge in the gap [20]. Under negative polarization, the faster negative ions and specially, the electrons are repelled from the negative electrode and conducted to ground, thus increasing the corona current. However, under positive polarity, the heavier and slower positive ions are also repelled from the positive electrode, and conducted to ground at a lower speed, whereas the electrons are involved in the discharge activity in the high field region around the positive electrode [4]. Positive corona pulses exhibit higher amplitudes than negative pulses, although the last ones are more frequent. This explains why the positive polarity corona current is lower than the negative one [33]. It is also known that negative corona exhibits more variability than positive corona because of the presence of discharge spots in variable locations [32].

\subsection{Peek's Law for Sphere-Plane Gap}

The well-known Peek's law, that applies for cylinders or conductors, relates the radius of the conductor or cylinder and the condition of its surface with the surface voltage gradient $E_{c}$ at the inception of visual corona [45] as,

$$
E_{c}=E_{0} \cdot m \cdot \delta(1+a / \sqrt{\delta \cdot r})
$$

where $E_{o}\left(\mathrm{kV}_{\text {peak }} / \mathrm{cm}\right.$ or $\left.\mathrm{kV}_{\mathrm{dc}} / \mathrm{mm}\right)$ is the visual critical voltage gradient measured at standard atmospheric conditions, $r(\mathrm{~cm})$ is the radius of the cylinder, $m$ a surface roughness factor and $\delta$ the relative air density ( $\delta=1$ under standard atmospheric conditions). According to Peek, at $50 / 60 \mathrm{~Hz}$, $E_{o}=30-31 \mathrm{kV}_{\text {peak }} / \mathrm{cm}$ and $a=0.301-0.308 \mathrm{~cm}^{1 / 2}$, depending on the specific cylindrical configuration.

It is noted that the experimental analysis performed in this work is based on samples with similar surface roughness factor $m$. All experimental results are transformed to standard atmospheric conditions, so $\delta=1$. Under these assumptions, this paper proposes an expression of the electric field on the surface of the spherical electrodes at the inception of visual corona similar to (1), which can be expressed as,

$$
E_{c}=b \cdot(1+c / \sqrt{r})
$$

The values of $b(\mathrm{kV} / \mathrm{cm})$ and $c\left(\mathrm{~cm}^{1 / 2}\right)$ must be obtained from experiments, and will depend on the nature of the applied voltage, that is ac, positive dc or negative dc.

\section{FEM Simulations}

FEM simulations allow calculation of the electric field strength around high-voltage electrodes. Although in this paper corona activity is not simulated using the FEM method, the geometric electric field strength just before corona appearance can be obtained once the experimental value of the voltage is known. By doing so, it is assumed that the electric field distribution is almost not affected by the space charge before corona appearance.

The three-dimensional geometry of the analyzed problem has to be prepared carefully and the boundary conditions well settled, as seen in Figure 1a. The electrostatics module of the commercial 
Comsol ${ }^{\circledR}$ package was used to solve the analyzed problem. This module solves the following equations in all points $(x, y, z)$ of the three-dimensional domain,

$$
\begin{gathered}
\nabla^{2} V(x, y, z)=-\rho / \varepsilon_{0} \\
E(x, y, z)=-\nabla V(x, y, z)
\end{gathered}
$$

$V$ and $E$ being respectively, the electric potential and the electric field, $\varepsilon_{0}$ the permittivity of air, and $\rho$ the charge density.

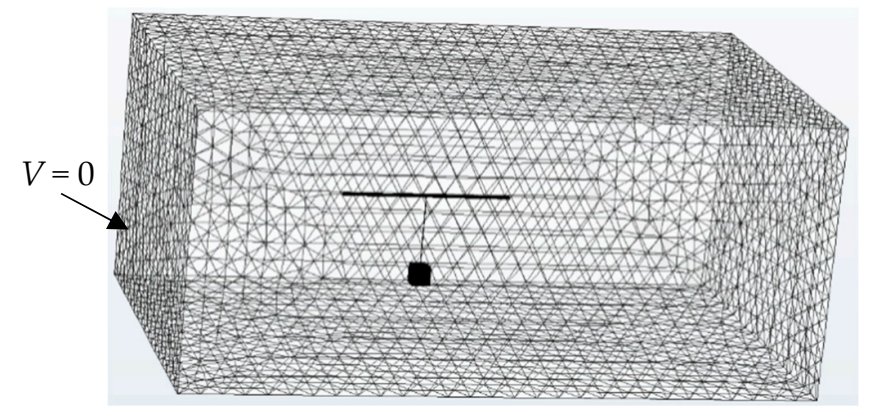

(a)

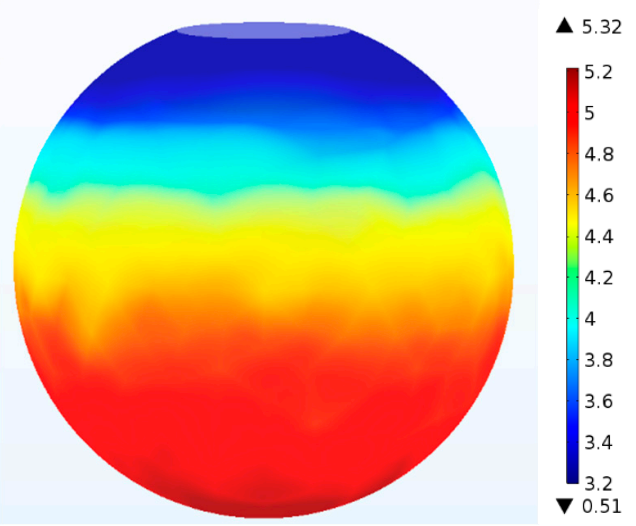

(b)
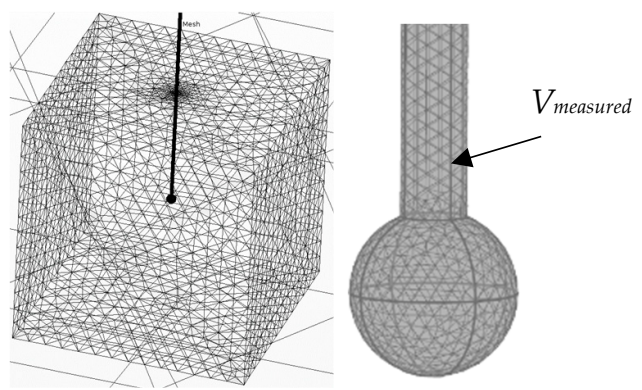
Experimental results summarized in this work are based on the voltage applied during visual corona extinction conditions, since it is the lower voltage at which corona effects can be measured. This visual corona extinction voltage was found by reducing progressively the voltage applied, from an initial voltage above the corona inception condition. Corona tests were performed with the high-voltage laboratory completely darkened. In order to increase the sensitivity of the measurements, large exposure photographs of 1 min were taken.

Atmospheric data were acquired by means of a calibrated Commeter D4130 digital thermos-hygrobarometer, which measures simultaneously the atmospheric pressure, relative humidity and temperature. Since visual corona inception and extinction voltage depends on the local atmospheric conditions [3], atmospheric corrections must be applied. These corrections were applied according to the procedure detailed in the IEEE Std 4-2013 standard [46], where the voltages measured under local atmospheric conditions are transformed to the standard atmosphere, that is, $20^{\circ} \mathrm{C}, 101.3 \mathrm{kPa}$ and $11 \mathrm{~g} / \mathrm{m}^{3}$.

A set of metallic spheres of approximate diameters $25,20,15,10,8,6,5,4$, and $3 \mathrm{~mm}$ were analyzed. Their exact dimensions are shown in Table 1. Each sphere was tested at different heights above the ground plane $(10,15,25,50$, and $75 \mathrm{~cm}$, as shown in Table 2). All tests were conducted under ac and positive and negative dc supply, and they were replicated three times and afterwards averaged.

The spheres were subjected by means of a hollow vertical metallic cylinder. Special care was taken to select the proper radius of the cylinder in order to ensure minimum effect of the cylinder in the results of the experiments. The selection of the suitable radius was made by means of FEM simulations and based on commercially available metallic tubes.

Figure 2 shows the experimental setup used to determine the visual corona extinction voltage.

Figure $2 \mathrm{~b}$ and Table 1 summarize the dimensions of the spheres analyzed in this work, as well as the radius of the vertical cylinder to hold the spheres.

Table 2 summarizes the different heights with respect to the ground plane at which the spheres where tested, as well as the height of the horizontal round bar of Figure 2b.

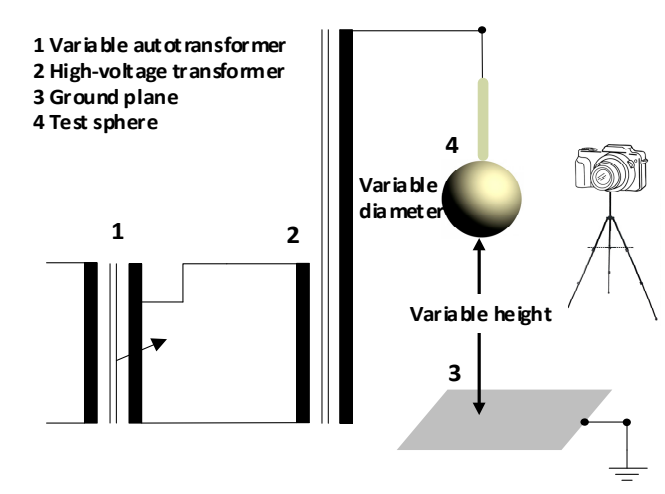

(a)

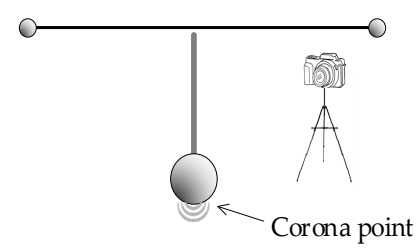

Visual corona tests

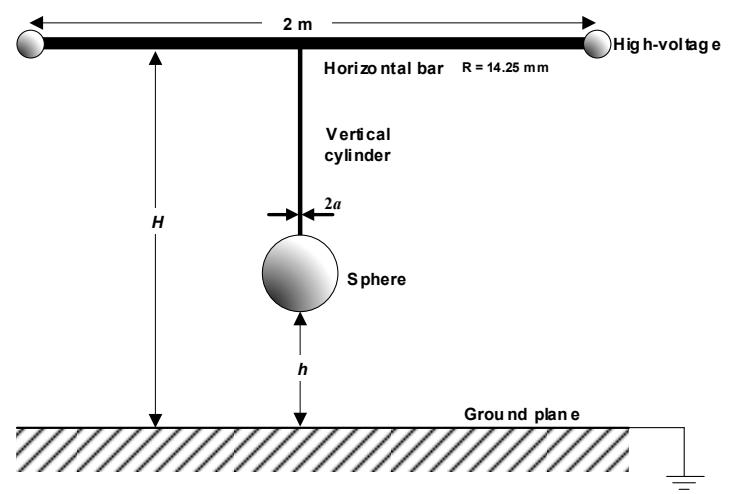

(b)

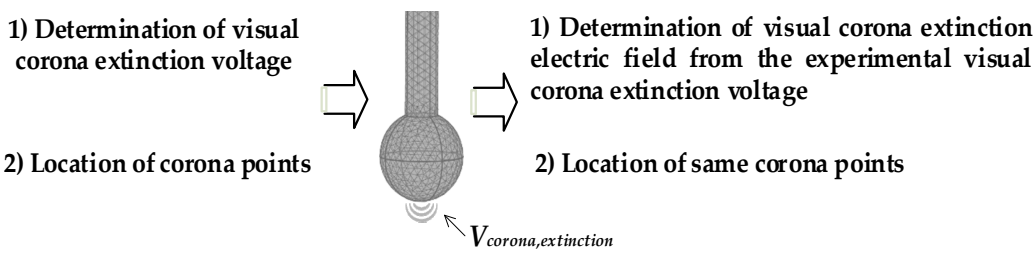

FEM simulations

(c)

Figure 2. (a) Experimental setup for ac tests. A similar setup was used for the direct current (dc) tests; (b) Sketch of the spherical electrode configuration; (c) Diagram of the proposed approach to determine the visual corona extinction electric field. FEM: Finite element method. 
Experimental tests have revealed that for positive polarity coronas, after inception, when the voltage increases, the corona seed point is gradually covered with a uniform glow. When the voltage is further increased, the glow mode transforms into a mode combining the glow and the formation of moving streamers. Finally, at higher voltages as seen in Figure 3, it can evolve into a disruptive discharge.

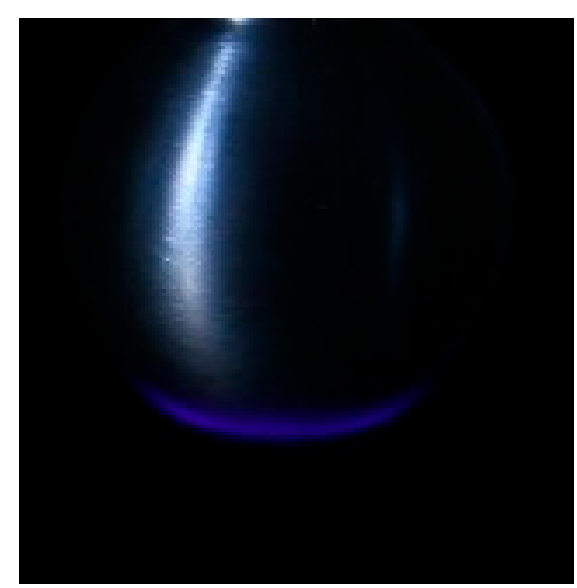

(a)

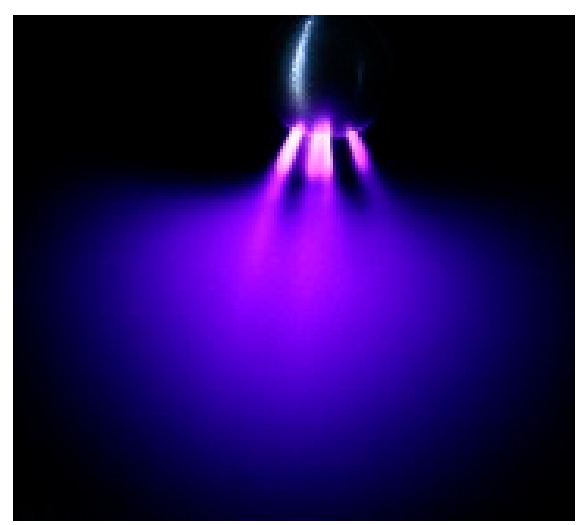

(c)

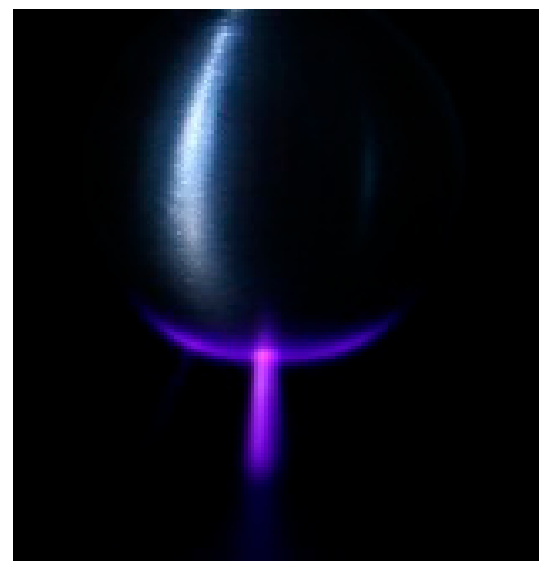

(b)

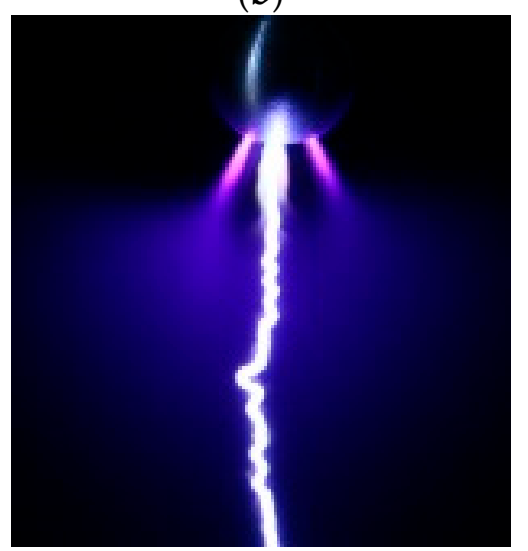

(d)

Figure 3. Positive polarity dc corona (sphere diameter of $20 \mathrm{~mm}, h=15 \mathrm{~cm}$ ). (a) Initial corona glow at $+55.5 \mathrm{kV}$; (b) Corona glow and streamer initiation at $+56.0 \mathrm{kV}$; (c) Advanced positive corona combining glow and streamers at $+62 \mathrm{kV}$; (d) Spark breakdown at approximately $+80 \mathrm{kV}$.

Table 1. Dimensions of Figure $2 b$.

\begin{tabular}{ccc}
\hline Approximate Diameter $(\mathbf{m m})$ & Actual Sphere Radius $(\boldsymbol{r}, \mathbf{m m})$ & Vertical Cylinder Radius $(a, \mathbf{m m})$ \\
\hline 25 & 12.3 & 2.9 \\
20 & 9.97 & 2.9 \\
15 & 7.24 & 2.9 \\
10 & 5.10 & 1.355 \\
8 & 3.90 & 1.355 \\
6 & 2.98 & 0.75 \\
5 & 2.48 & 0.75 \\
4 & 1.98 & 0.75 \\
3 & 1.48 & 0.75 \\
\hline
\end{tabular}


Table 2. Different heights of the spheres $(h)$ and the horizontal round bar $(H)$ in the experiments.

\begin{tabular}{cc}
\hline Test Height $(\boldsymbol{h}, \mathbf{c m})$ & $\boldsymbol{H} \mathbf{( c m})$ \\
\hline $10 \mathrm{~cm}$ & 79.5 \\
$15 \mathrm{~cm}$ & 79.5 \\
$25 \mathrm{~cm}$ & 79.5 \\
$50 \mathrm{~cm}$ & 145 \\
$75 \mathrm{~cm}$ & 166 \\
\hline
\end{tabular}

Negative dc corona usually shows more variability compared to positive dc or ac corona due to the presence of discharge spots in different locations [32], as shown in Figure 4. The tests carried out have shown that for negative coronas, after inception, one or several streamers, which are almost imperceptible, are formed in different locations of the sphere. As the voltage increases, more streamers are formed, thus increasing their density and length. The streamers move around the base of the spherical electrode, as depicted in Figure 4. It is noted that at $-130 \mathrm{kV}$, the output limit of the dc generator, there is still no disruptive breakdown.
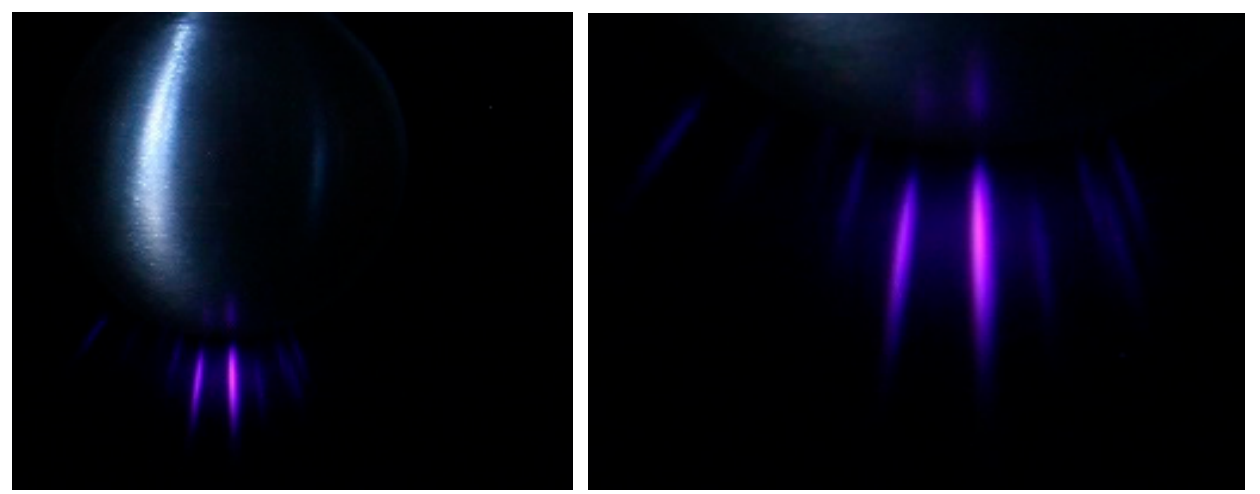

(a)

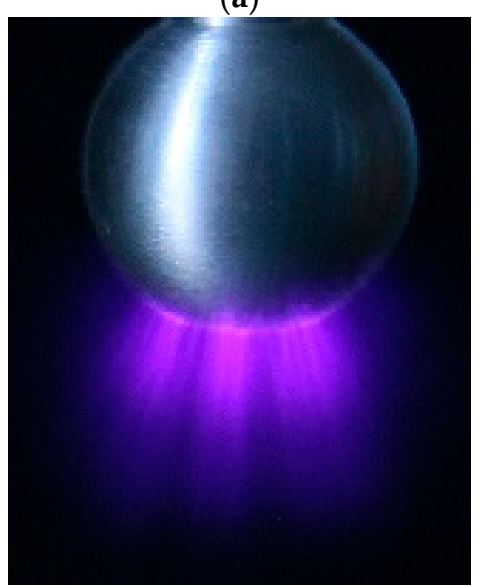

(b)

Figure 4. Negative polarity dc corona (sphere diameter of $20 \mathrm{~mm}, h=15 \mathrm{~cm}$ ). (a) Corona close to the extinction conditions $(-54.5 \mathrm{kV}$ ) with few moving streamers; (b) Advanced negative corona at $-75 \mathrm{kV}$ showing an amalgam of moving surface streamers.

Visual ac corona combines the effects of both, positive and negative dc corona, as shown in Figure 5. It initiates around a seed point, and when the voltage increases it combines the characteristics of both positive (steady glow mode) and negative (small moving streamers) corona until reaching the spark breakdown condition. 


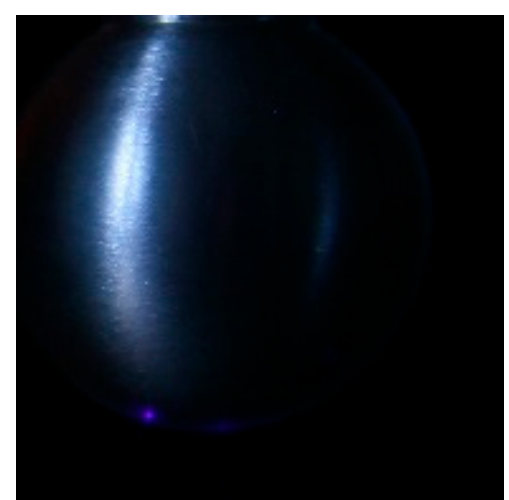

(a)

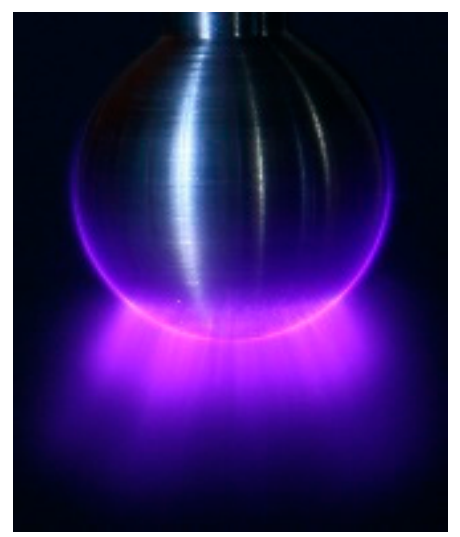

(c)

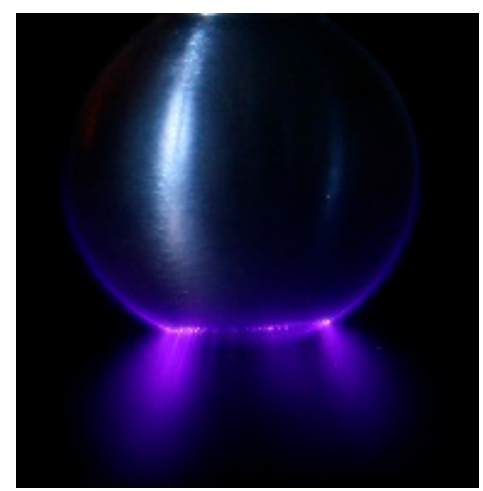

(b)

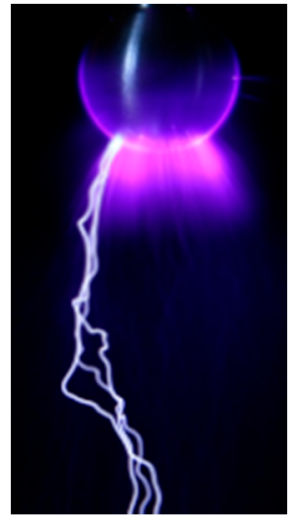

(d)

Figure 5. Alternating current corona (sphere diameter of $20 \mathrm{~mm}, h=25 \mathrm{~cm}$ ). (a) Initial corona at $59.0 \mathrm{kV}_{\text {peak; }}$ (b) Corona glow (positive semi-period corona) and moving streamers (negative semi-period corona) condition at $65.5 \mathrm{kV}_{\text {peak }}$; (c) Advanced corona combining corona glow and multitude of moving streamers at $75 \mathrm{kV}_{\text {peak }}$; (d) Spark breakdown at approximately $139 \mathrm{kV}_{\text {peak }}$.

\section{Sphere-Plane Gap Results}

This section shows the results attained by means of the visual corona tests under ac, positive and negative polarity dc supply. Whereas the visual corona voltage was directly measured during the experimental tests by means of the voltmeter integrated in the ac and dc generators, the surface electric field strength was obtained from FEM simulations. They were performed by replicating the experimental geometry and introducing the visual corona extinction voltage measured in the experimental tests. The results attained with the sphere-plane gap are summarized in Table 3.

Figure 6 shows a visual representation of the average results summarized in Table 1 referred to the ac visual corona extinction electric field strength. Results presented in Figure 6 show that in average, the positive dc visual corona extinction electric field strength is $3.3 \%$ higher compared to ac, whereas the negative dc visual corona extinction electric field is $4.2 \%$ lower than ac.

Figure 7 plot the surface electric field strength under visual corona extinction conditions for $50 \mathrm{~Hz}$ ac, positive dc and negative dc supply, as well as the regression curve according to the generalized Peek's law.

Experimental results presented in Figure 7 and Table 4 clearly show that the sphere-plane gap follows a correlation similar to Peek's law for cylindrical conductors. This conclusion is true for $50 \mathrm{~Hz}$ ac, positive dc and negative dc supply.

Power frequency ac corona appears under both positive and negative half-cycles of the voltage waveform. Figure 7 a shows that ac corona tends to fall between positive and negative dc corona. This result seems to be logical since the insulation has to withstand the positive and negative half-periods during the same time. 
Table 3. Summary of the experimental visual corona extinction voltage and the electric field strength obtained by means of FEM simulations under $50 \mathrm{~Hz}$ ac (peak values), positive polarity dc and negative polarity dc supply. ac: alternating current, dc: direct current.

\begin{tabular}{|c|c|c|c|c|c|c|c|c|c|c|}
\hline \multirow{2}{*}{$\begin{array}{l}\text { Diameter } \\
(\mathrm{mm})\end{array}$} & \multirow{2}{*}{$\begin{array}{c}\text { Sphere } \\
\text { Height } h(\mathrm{~m})\end{array}$} & \multicolumn{3}{|c|}{$\begin{array}{c}\text { Voltage Applied } \\
(\mathbf{k V})\end{array}$} & \multicolumn{3}{|c|}{$\begin{array}{c}E_{c}(\text { Corona Extinction } \\
\text { Electric Field) }(\mathrm{kV} / \mathrm{mm})\end{array}$} & \multicolumn{3}{|c|}{ Average $E_{c}(\mathrm{kV} / \mathrm{mm})$} \\
\hline & & dct & $\mathrm{dc}-$ & ac & dct & $\mathrm{dc}-$ & ac & dct & $\mathrm{dc}-$ & ac \\
\hline \multirow{5}{*}{$25 \mathrm{~mm}$} & 0.10 & $\mathrm{NO}$ & -56.4 & 56.6 & $\mathrm{NO}$ & -4.2 & 4.2 & \multirow{5}{*}{4.3} & \multirow{5}{*}{-3.9} & \multirow{5}{*}{4.1} \\
\hline & 0.15 & 64.5 & -57.0 & 58.8 & 4.5 & -4.0 & 4.1 & & & \\
\hline & 0.25 & 67.5 & -60.5 & 63.8 & 4.2 & -3.8 & 4.0 & & & \\
\hline & 0.50 & 70.3 & -62.2 & 67.2 & 4.3 & -3.8 & 4.1 & & & \\
\hline & 0.75 & 73.8 & -62.4 & 67.9 & 4.3 & -3.7 & 4.0 & & & \\
\hline \multirow{5}{*}{$20 \mathrm{~mm}$} & 0.10 & 50.8 & -46.7 & 50.3 & 4.3 & -4.0 & 4.3 & \multirow{5}{*}{4.4} & \multirow{5}{*}{-4.2} & \multirow{5}{*}{4.3} \\
\hline & 0.15 & 54.7 & -52.5 & 53.3 & 4.5 & -4.3 & 4.4 & & & \\
\hline & 0.25 & 58.2 & -57.5 & 57.1 & 4.4 & -4.3 & 4.3 & & & \\
\hline & 0.50 & 59.7 & -59.0 & 59.4 & 4.3 & -4.3 & 4.3 & & & \\
\hline & 0.75 & 61.4 & -61.3 & 61.3 & 4.3 & -4.3 & 4.3 & & & \\
\hline \multirow{5}{*}{$15 \mathrm{~mm}$} & 0.10 & 43.2 & -37.7 & 42.0 & 4.6 & -4.0 & 4.5 & \multirow{5}{*}{4.7} & \multirow{5}{*}{-4.3} & \multirow{5}{*}{4.5} \\
\hline & 0.15 & 45.0 & -41.7 & 40.6 & 4.9 & -4.5 & 4.4 & & & \\
\hline & 0.25 & 48.5 & -42.4 & 46.1 & 4.8 & -4.2 & 4.6 & & & \\
\hline & 0.50 & 48.2 & -45.0 & 46.7 & 4.6 & -4.3 & 4.5 & & & \\
\hline & 0.75 & 50.0 & -45.4 & 48.9 & 4.6 & -4.2 & 4.5 & & & \\
\hline \multirow{5}{*}{$10 \mathrm{~mm}$} & 0.10 & 32.3 & -31.0 & 32.5 & 5.0 & -4.8 & 5.0 & \multirow{5}{*}{4.9} & \multirow{5}{*}{-4.7} & \\
\hline & 0.15 & 34.8 & -31.9 & 34.5 & 5.0 & -4.6 & 5.0 & & & \\
\hline & 0.25 & 37.0 & -34.7 & 37.6 & 4.8 & -4.5 & 4.9 & & & 4.9 \\
\hline & 0.50 & 36.5 & -35.4 & 37.5 & 4.8 & -4.6 & 4.9 & & & \\
\hline & 0.75 & 38.7 & -37.2 & 37.9 & 5.0 & -4.8 & 4.9 & & & \\
\hline & 0.10 & 25.8 & -23.0 & 23.6 & 5.5 & -4.9 & 5.0 & & & \\
\hline & 0.15 & 26.9 & -24.7 & 25.6 & 5.3 & -4.8 & 5.0 & & & \\
\hline $8 \mathrm{~mm}$ & 0.25 & 29.2 & -27.1 & 27.1 & 5.3 & -4.9 & 4.9 & 5.3 & -5.0 & 5.1 \\
\hline & 0.50 & 29.4 & -28.4 & 29.0 & 5.2 & -5.0 & 5.1 & & & \\
\hline & 0.75 & 30.8 & -31.0 & 31.1 & 5.2 & -5.3 & 5.3 & & & \\
\hline & 0.10 & 22.6 & -20.5 & 20.6 & 5.8 & -5.3 & 5.3 & & & \\
\hline & 0.15 & 24.3 & -22.5 & 23.1 & 5.6 & -5.2 & 5.3 & & & \\
\hline $6 \mathrm{~mm}$ & 0.25 & 25.7 & -24.3 & 24.7 & 5.6 & -5.3 & 5.4 & 5.7 & -5.3 & 5.4 \\
\hline & 0.50 & 26.1 & -24.4 & 24.9 & 5.7 & -5.3 & 5.4 & & & \\
\hline & 0.75 & 27.0 & -25.2 & 25.6 & 5.8 & -5.4 & 5.5 & & & \\
\hline & 0.10 & 19.4 & -18.1 & 18.5 & 5.9 & -5.5 & 5.6 & & & \\
\hline & 0.15 & 20.2 & -18.8 & 19.8 & 5.8 & -5.4 & 5.7 & & & \\
\hline $5 \mathrm{~mm}$ & 0.25 & 21.6 & -19.9 & 20.5 & 5.8 & -5.3 & 5.5 & 5.8 & -5.4 & 5.6 \\
\hline & 0.50 & 22.1 & -21.0 & 21.9 & 5.8 & -5.5 & 5.7 & & & \\
\hline & 0.75 & 22.8 & -21.4 & 22.1 & 5.7 & -5.3 & 5.5 & & & \\
\hline & 0.10 & 16.7 & -15.9 & 15.0 & 6.1 & -5.8 & 5.5 & & & \\
\hline & 0.15 & 17.5 & -17.0 & 16.4 & 6.1 & -5.9 & 5.7 & & & \\
\hline $4 \mathrm{~mm}$ & 0.25 & 18.6 & -17.6 & 18.0 & 6.1 & -5.8 & 5.9 & 6.1 & -5.7 & 5.9 \\
\hline & 0.50 & 19.3 & -17.8 & 19.0 & 6.2 & -5.7 & 6.1 & & & \\
\hline & 0.75 & 20.3 & -18.1 & 20.6 & 6.1 & -5.4 & 6.2 & & & \\
\hline & 0.10 & 14.9 & -12.4 & 14.2 & 6.8 & -5.7 & 6.5 & & & \\
\hline & 0.15 & 15.4 & -13.5 & 14.7 & 6.8 & -6.0 & 6.5 & & & \\
\hline $3 \mathrm{~mm}$ & 0.25 & 16.6 & -15.0 & 16.8 & 6.8 & -6.2 & 6.9 & 6.8 & -6.0 & 6.7 \\
\hline & 0.50 & 17.2 & -15.5 & 17.4 & 6.8 & -6.1 & 6.9 & & & \\
\hline & 0.75 & 17.6 & -15.9 & 17.7 & 6.8 & -6.1 & 6.8 & & & \\
\hline
\end{tabular}


Table 4. Regression parameters of $E_{c}=b \cdot(1+c / \sqrt{r})$.

\begin{tabular}{cccc}
\hline Parameter & dc + & dc - & ac \\
\hline$b\left(\mathrm{kV}_{\text {peak }} / \mathrm{cm}\right)$ & $29.73(27.78,31.63)^{1}$ & $29.25(26.78,31.72)^{1}$ & $28.25(25.89,30.61)^{1}$ \\
$c\left(\mathrm{~cm}^{1 / 2}\right)$ & $0.485(0.417,0.553)^{1}$ & $0.421(0.338,0.504)^{1}$ & $0.505(0.416,0.595)^{1}$ \\
R-square $^{2}$ & 0.9926 & 0.9834 & 0.9887 \\
Adjusted R-square $^{2}$ & 0.9915 & 0.9811 & 0.9870 \\
SSE $^{2}$ & 4.171 & 6.860 & 6.282 \\
RMSE $^{2}$ & 0.772 & 0.990 & 0.947 \\
\hline
\end{tabular}

$195 \%$ confidence bounds; ${ }^{2}$ Goodness of fit statistics: SSE (sum of squares due to error), RMSE (root mean squared error).

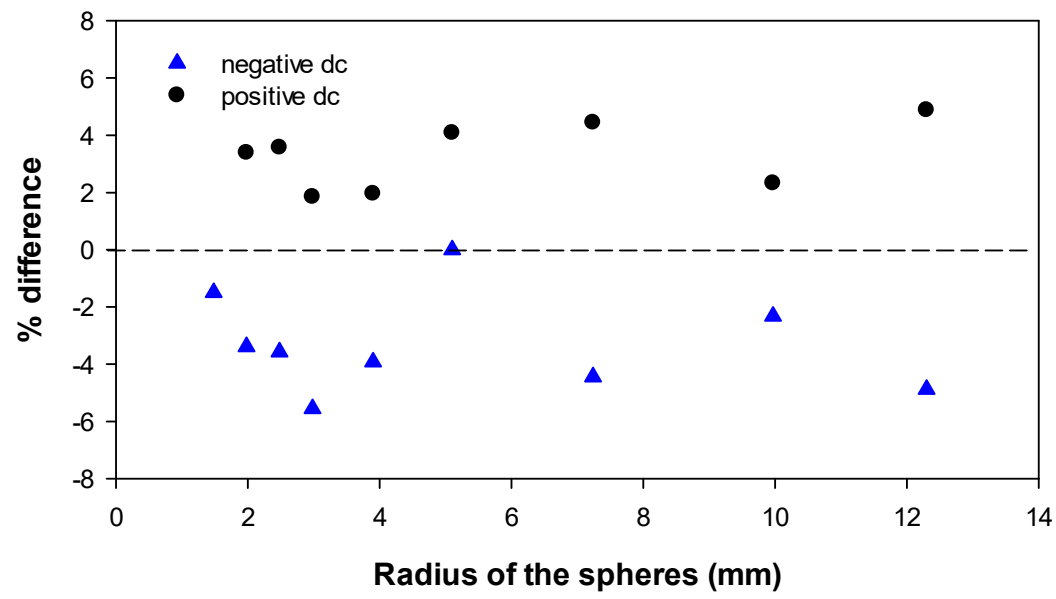

Figure 6. Percentage difference of the visual corona extinction electric field strength versus the curvature radius of the sphere. The ac value is taken as the reference.

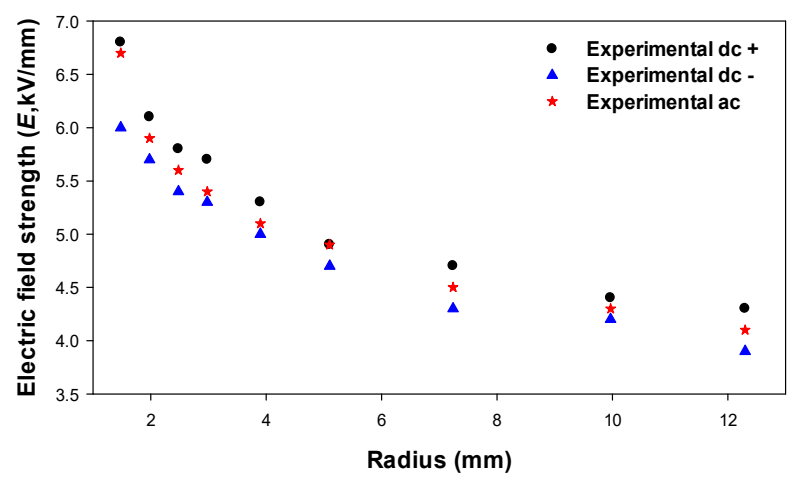

(a)

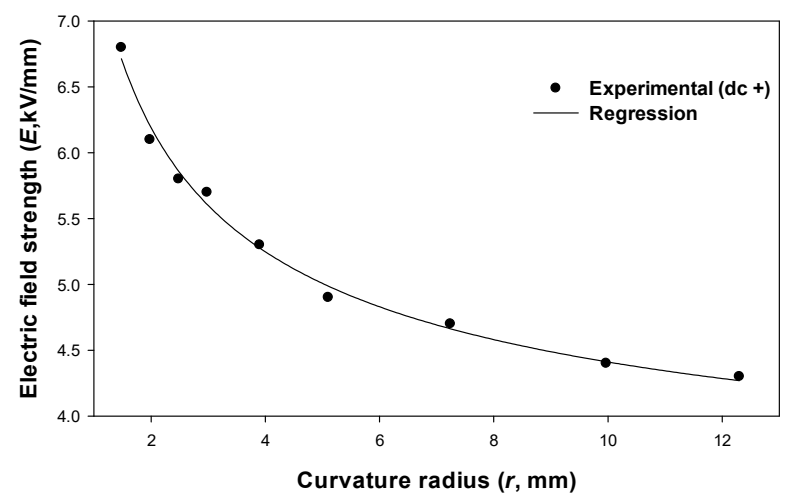

(b)

Figure 7. Cont. 


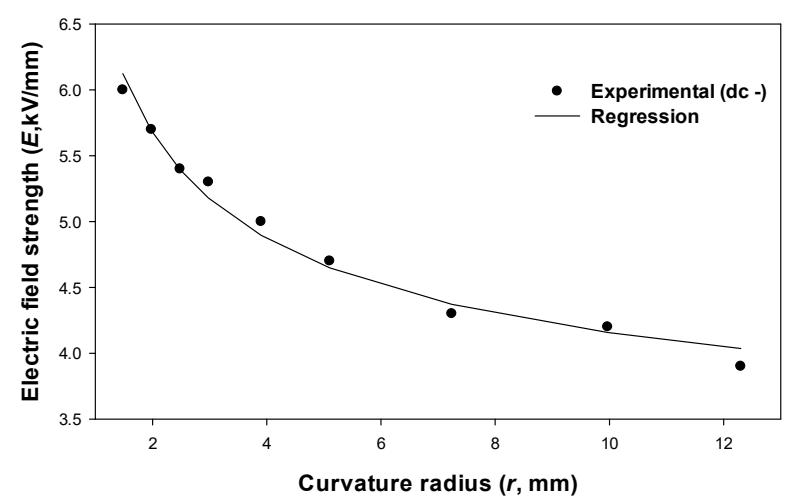

(c)

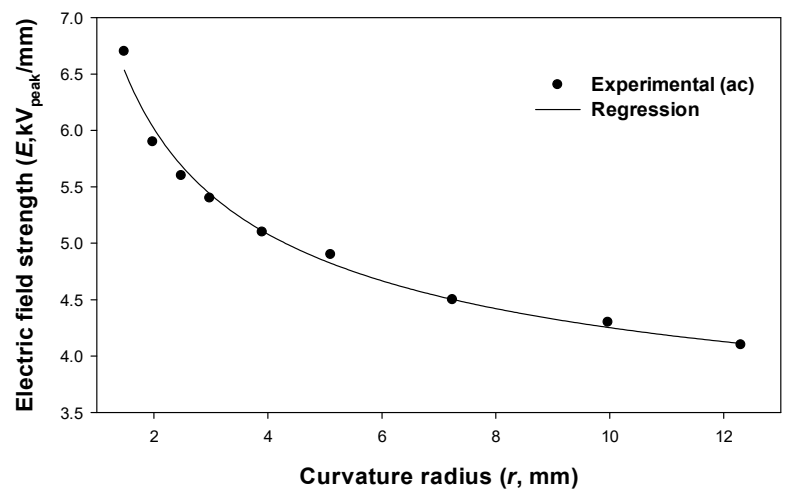

(d)

Figure 7. (a) Surface electric field strength versus the curvature radius of the sphere under corona extinction conditions for positive dc, negative dc and ac supply; (b) Peak curve regression for positive dc conditions; (c) Peak curve regression for negative dc conditions; (d) Peak curve regression for ac conditions.

\section{Substation Connector Results}

In this section a high-voltage substation connector is tested to validate and extrapolate the results obtained with the sphere-plane gap.

Figure 8 shows the T-type connector under test, with the conductors and the spherical corona protections at the end of the conductors.

Different corona tests were conducted on the substation connector under ac, positive and negative dc conditions. The results attained are summarized in Figures 9-11 and in Table 5.

Table 5. Visual corona extinction for the substation connector.

\begin{tabular}{cccc}
\hline Parameter & dc + & dc - & ac \\
\hline Extinction voltage $(\mathrm{kV}$ dc or peak $)$ & +84.9 & -77.0 & 81.3 \\
Electric field strength $(\mathrm{kV} / \mathrm{mm}$ dc or peak $)$ & 5.4 & -4.9 & 5.2 \\
\hline
\end{tabular}

Results presented in Table 5 show a similar behavior to those shown in Table 3, since the lowest visual extinction point corresponds to negative dc corona, whereas the highest one corresponds to positive dc corona, and so the visual ac extinction point falls between them. In addition, according to Table 3, the results presented in Table 5 correspond to radiuses in the range $4-8 \mathrm{~mm}$, which are corroborated in Figure $8 \mathrm{~d}$ (see the region with the red circle where corona starts). 


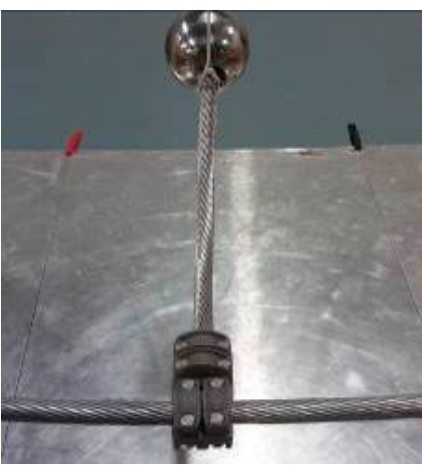

(a)

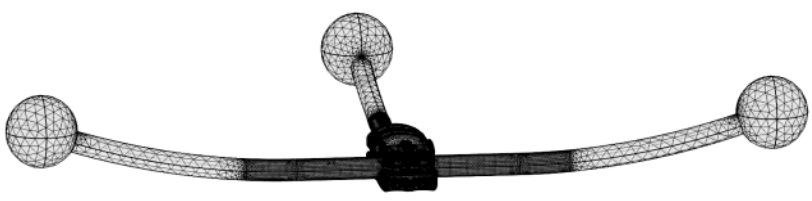

(b)

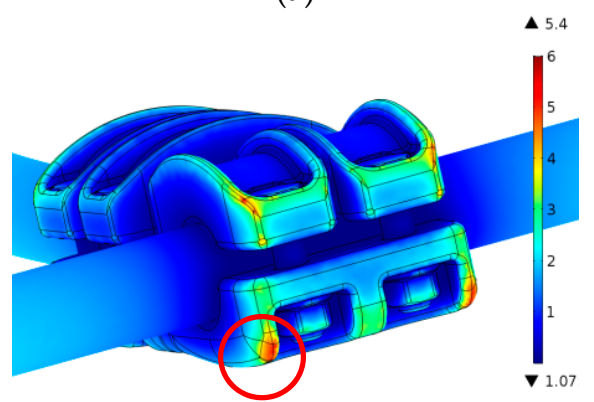

(c)

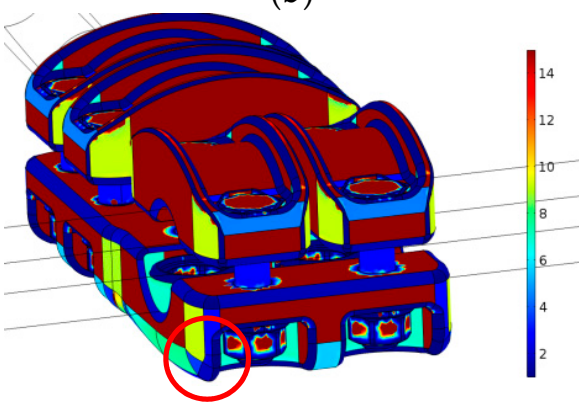

(d)

Figure 8. (a) Experimental layout with the center of the conductor placed at a height of $225 \mathrm{~mm}$ above the ground plane; (b) Mesh used in the FEM simulations of the connector, conductors and sphere corona protections; (c) Surface electric field in $\mathrm{kV} / \mathrm{mm}$ resulting from FEM simulations; (d) Geometrical radiuses of the connector in $\mathrm{mm}$.

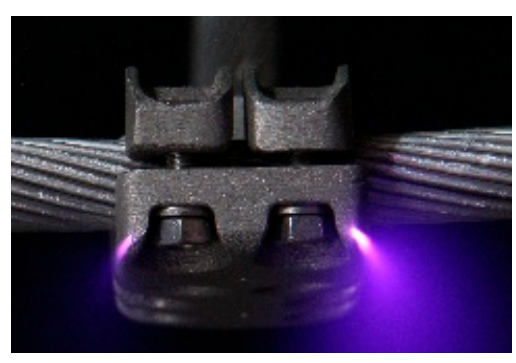

(a)

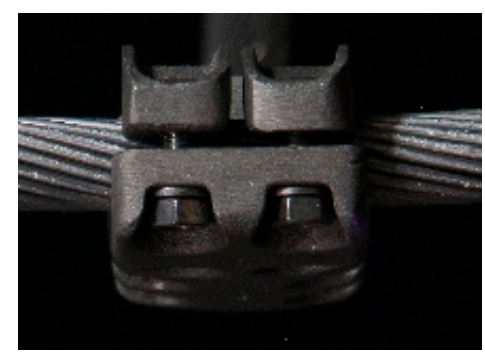

(b)

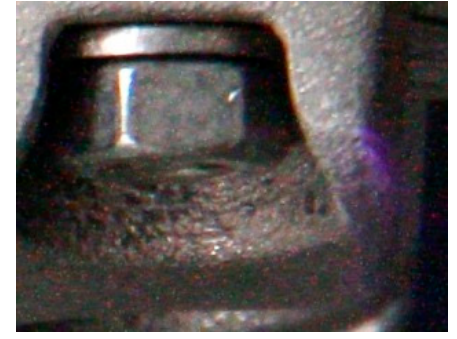

(c)

Figure 9. Corona tests. (a) Positive dc corona at $+90 \mathrm{kV}$; (b) Positive dc corona near the extinction point at $84.9 \mathrm{kV}$; (c) Zoom of Figure 9b.

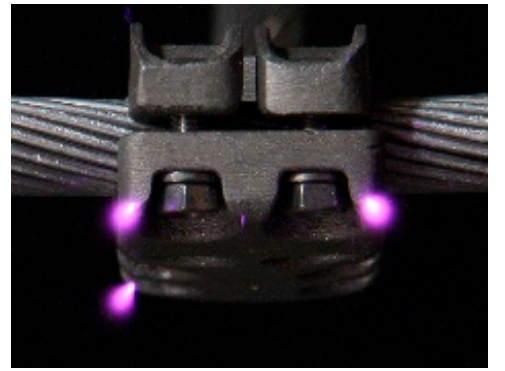

(a)

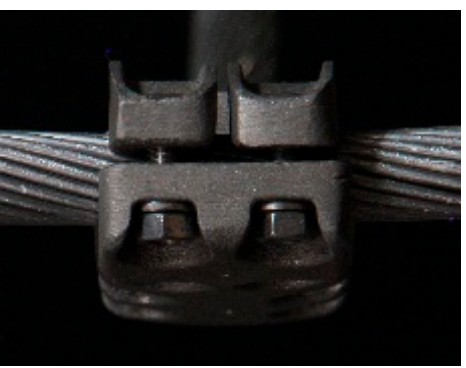

(b)

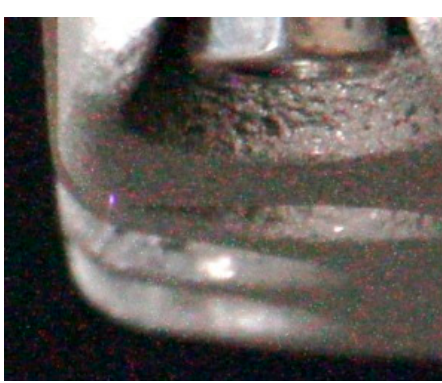

(c)

Figure 10. (a) Negative dc corona at $-100 \mathrm{kV}$; (b) Negative dc corona near the extinction point at $-77 \mathrm{kV}$; (c) Zoom of Figure 10b. 


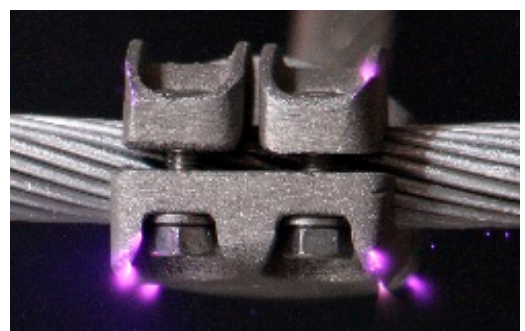

(a)

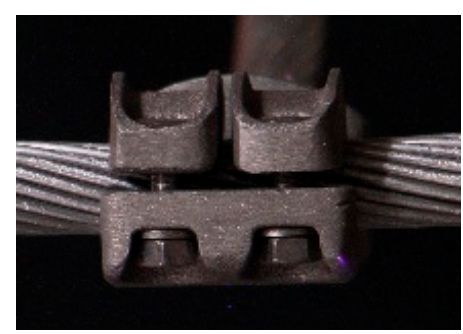

(b)

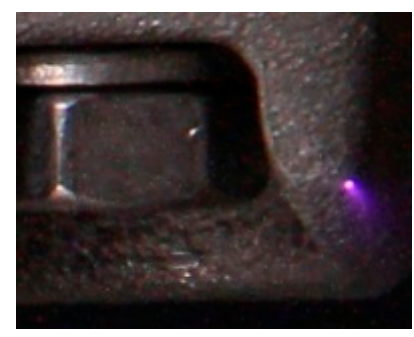

(c)

Figure 11. (a) ac corona at $77.75 \mathrm{kV}_{\mathrm{RMS}}$; (b) ac corona near the extinction point at $58.5 \mathrm{kV} \mathrm{RMS}_{\text {; }}$ (c) Zoom of Figure 11b.

\section{Conclusions}

The growing HVDC market is pushing many manufacturers of high-voltage hardware intended for power lines and electrical substations to focus their efforts towards this emerging market. To this end, studies correlating corona inception conditions under ac and dc supply are required, so that hardware designed for HVAC applications can be reused for HVDC projects.

This work has analyzed the sphere-plane air gap under atmospheric conditions, for different radiuses of the spherical electrodes in the range $3-25 \mathrm{~mm}$ of diameter placed at different heights above the ground plane, in the range 10 to $75 \mathrm{~cm}$. The experimental results combined with FEM simulations presented in this paper, clearly show that the sphere-plane gap follows a correlation similar to Peek's law for cylindrical conductors. This conclusion is true for $50 \mathrm{~Hz}$ ac, positive dc and negative dc supply. A case study based on a substation connector has also been analyzed, showing a similar corona behavior than that of the sphere-plane geometry, thus concluding that the results presented in this paper have a broader scope, since they can be extrapolated to other geometries. The experimental results summarized in this work could be useful for high-voltage hardware manufacturers, as a starting or reference point, to determine the voltage and electric field conditions at which their ac products can be applied under positive or negative dc supply.

Author Contributions: J.-R.R. conceptualized, designed and planed the experiments, A.M. and J.-R.R. performed the experimental tests, F.C. prepared the FEM simulations and J.-R.R. wrote the manuscript.

Funding: This research was funded by AGAUR under project reference 2017 SGR 967.

Acknowledgments: The authors thank SBI Connectors for providing part of the equipment and samples to perform the experimental tests.

Conflicts of Interest: The authors declare no conflict of interest.

\section{References}

1. Chan, J.K.; Kuffel, J.; Sibilant, G.C.; Bell, J.; Chan, J.K.; Bell, J.; Sibilant, G.C.; Chan, J.K.; Kuffel, J.; Sibilant, G.C.; et al. Methodology for HVDC corona tests. In Proceedings of the 2016 CIGRE-IEC Colloquium, Montréal, QC, Canada, 9-11 May 2016; pp. 1-10.

2. Zhang, C.; Yi, Y.; Wang, L. Positive DC corona inception on dielectric-coated stranded conductors in air. IET Sci. Meas. Technol. 2016, 10, 557-563.

3. Du, Z.; Huang, D.; Qiu, Z.; Shu, S.; Ruan, J.; Huang, D.; Shu, S.; Du, Z. Prediction study on positive DC corona onset voltage of rod-plane air gaps and its application to the design of valve hall fittings. IET Gener. Transm. Distrib. 2016, 10, 1519-1526.

4. Ijumba, N.M.; Lekganyane, M.J.; Britten, A.C. Comparative studies of DC corona losses in a corona cage and a point-plane gap. In Proceedings of the AFRICON 2007, Windhoek, South Africa, 26-28 September 2007; pp. 1-7.

5. Pedersen, A.; Lebeda, J.; Vibholm, S. Analysis of Spark Breakdown Characteristics for Sphere Gaps. IEEE Trans. Power Appar. Syst. 1967, 975-978. [CrossRef]

6. Li, Z.X.; Li, G.F.; Fan, J.B.; Yin, Y. Numerical calculation of the corona onset voltage for bundle conductors for HVDC transmission line. Eur. Trans. Electr. Power 2011, 21, 11-17. [CrossRef] 
7. Lu, T.; Xiong, G.; Cui, X.; Rao, H.; Wang, Q. Analysis of Corona Onset Electric Field Considering the Effect of Space Charges. IEEE Trans. Magn. 2011, 47, 1390-1393. [CrossRef]

8. Chen, J.; Davidson, J.H. Model of the Negative DC Corona Plasma: Comparison to the Positive DC Corona Plasma. Plasma Chem. Plasma Process. 2003, 23, 83-102. [CrossRef]

9. El-Bahy, M.M. Onset voltage of negative corona in point-cup gaps. In Proceedings of the Annual Report Conference on Electrical Insulation and Dielectric Phenomena, Cancun, Quintana Roo, Mexico, 20-24 October 2002; pp. 159-163.

10. Wang, Z.; Lu, T.; Cui, X.; Li, X.; Hiziroglu, H. Influence of AC voltage on the positive DC corona current pulses in a wire-cylinder gap View Documen. CSEE J. Power Energy Syst. 2016, 2, 58-65. [CrossRef]

11. Bian, X.; Yu, D.; Meng, X.; Macalpine, M.; Wang, L.; Guan, Z.; Yao, W.; Zhao, S. Corona-generated space charge effects on electric field distribution for an indoor corona cage and a monopolar test line. IEEE Trans. Dielectr. Electr. Insul. 2011, 18, 1767-1778. [CrossRef]

12. Hernández-Guiteras, J.; Riba, J.-R.; Casals-Torrens, P. Determination of the corona inception voltage in an extra high voltage substation connector. IEEE Trans. Dielectr. Electr. Insul. 2013, 20, 82-88. [CrossRef]

13. Goldman, M.; Sigmond, R. Corona and Insulation. IEEE Trans. Electr. Insul. 1982, 90-105. [CrossRef]

14. Janischewschkyj, W.; Maruvada, P.S.; Gela, G. Corona losses and ionized fields of HVDC transmission lines. In Proceedings of the International Conference on Large High Voltage Electric Systems, Paris, France, 1-9 September 1982.

15. Wadhwa, C.L. High Voltage Engineering; Butterworth-Heinemann: Oxford, UK, 2010.

16. Chang, J.-S.; Lawless, P.A.; Yamamoto, T. Corona discharge processes. IEEE Trans. Plasma Sci. 1991, 19, 1152-1166. [CrossRef]

17. Hwang, S.; Lee, J.; Jang, G.; Hwang, S.; Lee, J.; Jang, G. HVDC-System-Interaction Assessment through Line-Flow Change-Distribution Factor and Transient-Stability Analysis at Planning Stage. Energies 2016, 9, 1068. [CrossRef]

18. Parisot, A.; Boden, M.; Sommantico, G.; Abildgaard, E. Recommended Voltages for HVDC Grids; Technical Brochure; e-cigré: Paris, France, June 2017; Volume 292.

19. Liu, M.; Tang, J.; Yao, Q.; Miao, Y. Development processes of positive and negative DC corona under needle-plate electrode in air. In Proceedings of the 2016 IEEE International Conference on High Voltage Engineering and Application (ICHVE), Chengdu, China, 19-22 September 2016; pp. 1-4.

20. Wais, S.I.; Giliyana, D.D. Sphere-to-Plane Electrodes Configuration of Positive and Negative Plasma Corona Discharge. Am. J. Mod. Phys. 2013, 2, 46-52. [CrossRef]

21. Zhang, Y.; Liu, L.; Chen, Y.; Ouyang, J. Characteristics of ionic wind in needle-to-ring corona discharge. J. Electrostat. 2015, 74, 15-20. [CrossRef]

22. Fromm, U. Partial Discharge and Breakdown Testing at High DC Voltage. Ph.D. Thesis, Delft University Press, Delft, The Netherlands, 19 September 1995.

23. Fuangpian, P.; Zafar, T.; Ruankorn, S.; Suwanasri, T. Experimental Investigation of the Corona Discharge in Electrical Transmission due to AC/DC Electric Fields. In Proceedings of the 2016 4th International Conference on Electrical Energy and Networks (ICEEN 2016), Nice, France, 18-19 February 2016.

24. Riba, J.-R.; Abomailek, C.; Casals-Torrens, P.; Capelli, F. Simplification and cost reduction of visual corona tests. IET Gener. Transm. Distrib. 2018, 12, 834-841. [CrossRef]

25. Becan, M.; Babuder, M.; Vizintin, S.; Kobal, I. Corona Performance of $400 \mathrm{kV}$ Bundle Conductors and Insulator Strings; Report B2-112; CIGRE: Paris, France, 2014; pp. 1-9.

26. Chen, L.; MacAlpine, J.M.K.; Bian, X.; Wang, L.; Guan, Z. Comparison of methods for determining corona inception voltages of transmission line conductors. J. Electrostat. 2013, 71, 269-275. [CrossRef]

27. Souza, A.L.; Lopes, I.J.S. Experimental investigation of corona onset in contaminated polymer surfaces. IEEE Trans. Dielectr. Electr. Insul. 2015, 22, 1321-1331. [CrossRef]

28. Dong, M.; Wang, B.; Ren, M.; Zhang, C.; Zhao, W.; Albarracin, R. Joint Visualization Diagnosis of Outdoor Insulation Status with Optical and Acoustical Detections. IEEE Trans. Power Deliv. 2018. [CrossRef]

29. Robles, G.; Fresno, J.; Sánchez-Fernández, M.; Martínez-Tarifa, J.; Robles, G.; Fresno, J.M.; Sánchez-Fernández, M.; Martínez-Tarifa, J.M. Antenna Deployment for the Localization of Partial Discharges in Open-Air Substations. Sensors 2016, 16, 541. [CrossRef] [PubMed] 
30. Pihera, J.; Trnka, P.; Kozak, O.; Hornak, J. Pulse sequence analysis of corona discharge at DC voltage. In Proceedings of the 2016 Diagnostic of Electrical Machines and Insulating Systems in Electrical Engineering (DEMISEE), Papradno, Slovakia, 20-22 June 2016; pp. 71-76.

31. Mikropoulos, P.; Zagkanas, V. Threshold inception conditions for positive DC corona in the coaxial cylindrical electrode arrangement under variable atmospheric conditions. IEEE Trans. Dielectr. Electr. Insul. 2015, 22, 278-286. [CrossRef]

32. Waters, R.T.; Rickard, T.E.S.; Stark, W.B. Direct measurement of electric field at line conductors during a.c. corona. Proc. Inst. Electr. Eng. 1972, 119, 717. [CrossRef]

33. Maglaras, A.L.; Maglaras, L.A. The polarity effect and the corona current in small air gaps. In Proceedings of the 2nd International Conference on Experiments/Process/System Modelling/Simulation and Optimization, Athens, Greece, 4-7 July 2007; pp. 1-9.

34. Plank, T. Positive Corona at Combined DC and AC Voltage; University of Tartu: Tartu, Estonia, 2002.

35. Zhang, Y.; Xia, Q.; Jiang, Z.; Ouyang, J. Trichel pulse in various gases and the key factor for its formation. Sci. Rep. 2017, 7. [CrossRef] [PubMed]

36. Chen, J.; Davidson, J.H. Ozone Production in the Negative DC Corona: The Dependence of Discharge Polarity. Plasma Chem. Plasma Process. 2003, 23, 501-518. [CrossRef]

37. Pekárek, S. Effect of polarity on ozone production of DC corona discharge with and without photocatalyst. Int. Symposium Plasma Chem. 2009, 19, 1-4.

38. Briels, T.M.P.; Kos, J.; Winands, G.J.J.; van Veldhuizen, E.M.; Ebert, U. Positive and negative streamers in ambient air: Measuring diameter, velocity and dissipated energy. J. Phys. D Appl. Phys. 2008, 41. [CrossRef]

39. Mikropoulos, P.N.; Zagkanas, V.N. Negative DC corona inception in coaxial cylinders under variable atmospheric conditions: A comparison with positive corona. IEEE Trans. Dielectr. Electr. Insul. 2016, 23, 1322-1330. [CrossRef]

40. International Electrotechnical Commission. IEC 61284: 1997 Overhead Lines-Requirements and Tests for Fittings; International Electrotechnical Commission: Geneva, Switzerland, 17 September 1997.

41. IEEE PES Transmission \& Distribution Committee. IEEE Std 1829-2017-IEEE Guide for Conducting Corona Tests on Hardware for Overhead Transmission Lines and Substations; IEEE Power and Energy Society: Piscataway, NJ, USA, 14 February 2017.

42. Kuffel, J.; Zaengl, W.S.; Kuffel, P. High Voltage Engineering Fundamentals, 2nd ed.; Newnes: Oxford, UK, 2000.

43. Electric Research Council. Transmission Line Reference Book $345 \mathrm{kV}$ and Above; Electric Power Research Institute (EPRI): Palo Alto, CA, USA, 2014.

44. Abdel-Salam, M.; Nakano, M.; Mizuno, A. Electric fields and corona currents in needle-to-meshed plate gaps. J. Phys. D Appl. Phys. 2007, 40, 3363-3370. [CrossRef]

45. Peek, F.W. The Law of Corona and the Dielectric Strength of Air-II. Proc. Am. Inst. Electr. Eng. 1912, 1051-1092. [CrossRef]

46. IEEE. IEEE Std 4-2013 (Revision of IEEE Std 4-1995) IEEE Standard for High-Voltage Testing Techniques; IEEE: Piscataway, NJ, USA, 2013; pp. 1-213.

(c) 2018 by the authors. Licensee MDPI, Basel, Switzerland. This article is an open access article distributed under the terms and conditions of the Creative Commons Attribution (CC BY) license (http://creativecommons.org/licenses/by/4.0/). 